\section{Lymphangioma of the Colon Treated by Endoscopic Resection Following Fine-Needle Puncture Aspiration}

A 47-year-old Japanese man was admitted for further evaluation of positive fecal occult blood observed during a routine medical health check. A barium enema study demonstrated a smooth, lobulated, sessile polypoid tumor, $45 \mathrm{~mm}$ in diameter, in the transverse colon. Endoscopy showed a lobulated, hemispherical tumor, which was an easily deformed, fluid-filled blister with a grayish-white transparency (Figure 1). The endoscopic ultrasound probe (Aloka, SSD-550, $15 \mathrm{MHz}$ ) demonstrated a multilocular anechoic area in the submucosa (Figure 2). These findings were suggestive of lymphangioma. Using a needle-tipped catheter, $3 \mathrm{ml}$ of yellowishwhite cystic fluid was aspirated from the tumor. A second endoscopy, two months later, showed that the tumor had shrunk as a result of the puncture aspiration. With intraluminal air being gradually deflated, the tumor was snared at its base with a thorn-attached snare (Olympus, SD-16U), then electrocauterized with blended current, and resected without any complications. The histological examination revealed a submucosal tumor composed of lymphatic vessels of various sizes -findings consistent with cavernous lymphangioma. Two months later, endoscopy revealed a red ulcer scar at the resection site, with no residual tumor (Figure 3).

Since colonic lymphangioma has caused complications such as intussusception, stenosis, massive bleeding, and protein-losing enteropathy $(1,2)$, treatment has consisted of segmental colectomy and local excision in as many as $60 \%$ of cases in Japan (3). However, considering that no malignant cases have been reported in the literature $(3,4)$, so that invasive surgery should be avoided as much as possible, endoscopic resection has been increasingly performed on tumors of less than $20 \mathrm{~mm}$ in diameter $(3,4)$. Karasawa et al. observed tumor volume reduction at the second endoscopy due to the outflow of cystic fluid caused by a preceding forceps biopsy (5). With the technique presented here, even sessile lymphangiomas of more than $20 \mathrm{~mm}$ in diameter can be resected endoscopically.

The precondition for endoscopic resection is that the tumor should be confined to the submucosa. At presentation, some lymphangiomas have, however, already penetrated beyond the sumucosa, into the muscularis propria or the mesentery $(1,2)$. Endosonography is recommended to assess the endoscopic resectability.

H. Yoshikane'. E. Hamajima', T. Yokoi'․, T. Suzuki', H. leda'. N. Mivachi', A. Fukui ${ }^{3}$

${ }^{1}$ Dept. of Internal Medicine

${ }^{2}$ Dept. of Pathology, Kariya General Hospital, Kariya, Japan

${ }^{3}$ Toyoda Machine Works Medical Office, Kariya, Japan

\section{References}

1. Yoshitoshi Y, Oda T, Utsumi Y, et al. A case of lymphangioma of the ascending colon [in Japanese with English abstract]. Nippon Rinsho [Jpn J Clin Med] 1965; 23: 2264-7.

2. Zilko PJ, Laurence MB, Sheiner H, et al. Cystic lymphangioma of the colon causing protein-losing enteropathy. Am J Dig Dis 1975; 20: 1076-80.

3. Saeki T, Fukuda T, Inoue S, et al. Lymphangioma of the ascending colon: a report of two cases resected by endoscopic polypectomy and review of the literature [in Japanese with English abstract]. Gastroenterol Endosc 1991: 33: 1409-16.

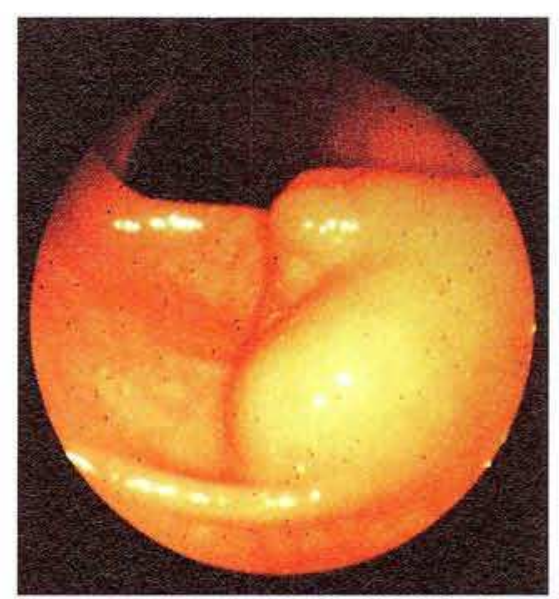

Figure 1: Endoscopic view of a lobulated, hemispherical tumor. It was an easily deformed, fluidfilled blister, with a grayish-white transparency.



Figure 2: The endoscopic ultrasound probe demonstrating a multilocula anechoic area (arrowheads) in the submucosa (sm), with an intact muscularis propria layer ( $\mathrm{mp}$ )



Figure 3: Endoscopic view showing a red ulcer scar at the resection site, with no residual turner. 
4. Nakagawara G, Kojima Y, Mai M, et al. Lymphangioma of the transverse colon treated by transendoscopic polypectomy: report of a case and review of literature. Dis Colon Rectum 1981; 24: $291-5$

5. Karasawa H, Miura T, Makino T, et al. Two cases of lymphangioma of the large intestine extracted by endoscopic polypectomy [in Japanese with English abstract]. Prog Dig Endosc $1985 ; 26: 330-4$.
Corresponding Author

H. Yoshikane, M.D.

Dept. of Internal Medicine

Kariya General Hospital

5-Sumiyoshi-cho

Kariya City

Japan

Fax: $+81-566-22-2493$ 